GARCIA Y GARCIA (Laurentino), Pupils, teachers and schools in Pompei. Childhood, youth and culture in the Roman era

Edited by Maria Elisa Garcia Barraco, Rome : Bardi editore, 2005. 173 p.

Pascale Hummel

\title{
OpenEdition
}

Journals

Édition électronique

URL : https://journals.openedition.org/histoire-education/1795

DOI : $10.4000 /$ histoire-education. 1795

ISSN : 2102-5452

Éditeur

ENS Éditions

Édition imprimée

Date de publication : 1 janvier 2009

Pagination : 121-123

ISBN : $979-2-7342-1142-6$

ISSN : 0221-6280

Référence électronique

Pascale Hummel, «GARCIA Y GARCIA (Laurentino), Pupils, teachers and schools in Pompei. Childhood, youth and culture in the Roman era », Histoire de l'éducation [En ligne], 121 | 2009, mis en ligne le 20 mai 2009, consulté le 20 mai 2021. URL : http://journals.openedition.org/histoire-education/1795 ; DOI :

https://doi.org/10.4000/histoire-education.1795

Ce document a été généré automatiquement le 20 mai 2021.

(c) Tous droits réservés 


\section{GARCIA Y GARCIA (Laurentino), Pupils, teachers and schools in Pompei. Childhood, youth and culture in the Roman era}

Edited by Maria Elisa Garcia Barraco, Rome : Bardi editore, 2005. 173 p.

\section{Pascale Hummel}

\section{RÉFÉRENCE}

GARCIA Y GARCIA (Laurentino), Pupils, teachers and schools in Pompei. Childhood, youth and culture in the Roman era. Edited by Maria Elisa Garcia Barraco, Rome : Bardi editore, $2005.173 \mathrm{p}$.

1 La ville de Pompéi, en tant que centre géographique et historique, est au cœur de ce livre, plus particulièrement à travers le lien entre éducation et vie quotidienne, abordé par le biais des peintures et des objets. La culture romaine est rurale, rappelle l'auteur : une place importante y est accordée à la tradition, aux anciens et à la transmission orale. La première éducation se déroule dans la famille, où l'autorité incontestée du pater familias s'allie à une révérence presque sacrée envers la mère.

2 Dans la Pompéi osque et pré-romaine, l'éducation est de type hellénistique, fortement influencée par le modèle grec. L'élève suit successivement l'enseignement du magister, ou litterator; du grammaticus; de l'orator, ou du rhetor. La première école payante a sans doute été fondée par Spurius Carvilius. Les lieux où les élèves se rassemblent sont souvent fort simples, les classes se tiennent en plein air, sous les portiques, ou dans des espaces fermés par des cloisons. La réalité des écoles publiques est attestée par les fresques (représentant, par exemple, des portiques). L'école à domicile est illustrée par le cas du grammaticus Iulius Helenus, les nombreux graffiti (citations de poètes), l'Hortulus du ludimagister et grammaticus Potitus (dessins, gravures, 
reconstitutions graphiques diverses, frises décoratives). Les enfants des meilleures familles pompéiennes sont envoyés à Rome ou dans la docta Neapolis.

3 L'année scolaire commence en mars, le premier mois du calendrier romain, avec une interruption de fin juillet à mi-octobre pour les vacances. L'élève se rend à l'école, accompagné d'un pédagogue (paedagogus, custos) et d'un esclave (verna ou vernula). Les cours ont surtout lieu le matin, en tout cinq ou six heures par jour; la journée se termine par le bain. Les Hermeneumata (manuels de conversation) représentent une source importante pour toutes ces données. L'apprentissage de l'alphabet, selon une méthode mnémotechnique, englobe aussi bien le latin (vingt et un signes) que le grec, et parfois l'osque. Les enfants écrivent sur une tablette de cire, incisant les lettres avec un stylus. Différentes méthodes, attestées par des documents en provenance d'Égypte, président à l'apprentissage de l'écriture, où le maître conduit la main de l'élève (ductus) : par lettres isolées, syllabes, ou mots, etc. Puis les enfants apprennent à se servir du calamus. À l'école primaire, les mathématiques et le calcul sont enseignés au même titre que la langue; le système duodécimal est employé, le chiffre zéro est inconnu. Le boulier (abacus) fait partie de la panoplie du jeune Romain. Le stade intermédiaire comporte l'apprentissage de la grammaire, de l'histoire, de la géographie, de la littérature, et des rudiments de la physique. L'usage de la ferula et des châtiments corporels (catomidiare) n'est pas rare.

4 Après les élèves, l'auteur évoque, en s'appuyant sur des témoignages épigraphiques, les enseignants, en grande partie d'origine grecque ou hellénistique, parce que plus érudits que le commun des citoyens romains. Beaucoup sont des esclaves et ne jouissent d'aucun statut particulier, vivant même dans la pauvreté. L'enseignant de l'école primaire est magister, ludimagister ou litterator. Le maître de l'enseignement secondaire est le grammaticus qui, malgré un meilleur salaire, ne jouit d'aucune véritable aisance matérielle. Les élèves se présentent ensuite devant les rhetores, ou les iuri doctores - voire un procureur, causidicus - s'ils veulent étudier le droit.

5 Les inscriptions permettent d'apprécier le degré de culture, de savoir et de maitrise de la langue; elles reflètent la survivance de la langue osco-samnite. Dans l'orthographe apparait une riche gamme de fautes possibles; la connaissance du grec est également un indice du niveau culturel atteint. Les graffiti, qui empruntent autant à la prose qu'à la poésie, à la littérature grecque que latine, reflètent la culture littéraire et philosophique des habitants de Pompéi, ainsi que leur culture technique et scientifique. La présence de rouleaux, stylets et autres attributs du savoir dans les peintures et les fresques souligne l'omniprésence d'un imaginaire de la pratique «lettrée » ou "scolaire ». La jeunesse de Pompéi, souvent à l'origine des inscriptions murales, affirme son identité à travers des associations et des confréries, dont la structure est influencée par le modèle grec.

6 Matériellement, le livre de L. Garcia y Garcia (traduit de l'italien en anglais, avec quelques maladresses) est un objet superbe, imprimé sur papier glacé : l'iconographie, riche, pertinente et abondante (presque à toutes les pages ou toutes les deux pages) constitue l'attrait principal de l'ouvrage. Intellectuellement, cependant, le contenu n'est pas tout à fait ce qu'un lecteur averti est en droit d'attendre d'un travail à prétention érudite ou universitaire. Les faits rappelés par l'auteur ne sont ni neufs, ni originaux pour qui connaît (de près ou de loin) le sujet traité; leur présentation manque même par endroits de rigueur et de précision. C'est l'iconographie qui fait l'intérêt principal de ce livre, à consulter d'abord comme un livre d'images. 


\section{AUTEURS}

PASCALE HUMMEL 